\title{
Nanoscale Mechanism
}

National Cancer Institute

\section{Source}

National Cancer Institute. Nanoscale Mechanism. NCI Thesaurus. Code C62348.

The process underlying a biological, chemical or physical nanoscale phenomenon. 